\title{
Molecular and clinical analyses of 84 patients with tuberous sclerosis
} complex

\author{
Chia-Cheng Hung ${ }^{\dagger 1}$, Yi-Ning Su ${ }^{\dagger 2,10, ~ S h u-C h i n ~ C h i e n ~}{ }^{3}$, Horng-Huei Liou ${ }^{4,5}$, \\ Chih-Chuan Chen ${ }^{4}$, Pau-Chung Chen ${ }^{6}$, Chia-Jung Hsieh ${ }^{6}$, Chih-Ping Chen ${ }^{7}$, \\ Wang-Tso Lee ${ }^{8}$, Win-Li Lin ${ }^{1}$ and Chien-Nan Lee*9
}

\begin{abstract}
Address: ${ }^{1}$ Institute of Biomedical Engineering, College of Medicine and College of Engineering, National Taiwan University, Taipei, Taiwan, 2Department of Medical Genetics, National Taiwan University Hospital, Taipei, Taiwan, ${ }^{3}$ Departments of Medical Genetics and Obstetrics and Gynecology, China Medical University Hospital, Taichung, Taiwan, ${ }^{4}$ Department of Neurology, National Taiwan University Hospital, Taipei, Taiwan, ${ }^{5}$ Department of Pharmacology, College of Medicine, National Taiwan University, Taipei, Taiwan, ${ }^{6}$ Institute of Occupational Medicine and Industrial Hygiene, National Taiwan University College of Public Health, Taipei, Taiwan, ${ }^{7}$ Department of Obstetrics and Gynecology, Mackay Memorial Hospital, Taipei, Taiwan, ${ }^{8}$ Department of Pediatrics, National Taiwan University Hospital, Taipei, Taiwan, ${ }^{9}$ Department of Obstetrics and Gynecology, National Taiwan University Hospital, Taipei, Taiwan and ${ }^{10}$ Graduate Institute of Clinical Medicine, College of Medicine, National Taiwan University, Taipei, Taiwan

Email: Chia-Cheng Hung - r91548020@ntu.edu.tw; Yi-Ning Su - ynsu@ntumc.org; Shu-Chin Chien - chien-sc@yahoo.com.tw; HorngHuei Liou - liou@ha.mc.ntu.edu.tw; Chih-Chuan Chen - chihch@ha.mc.ntu.edu.tw; Pau-Chung Chen - pchen@ntu.edu.tw; ChiaJung Hsieh - r92841014@ntu.edu.tw; Chih-Ping Chen - cpc_mmh@yahoo.com; Wang-Tso Lee - leeped@hotmail.com; Win-

Li Lin - winli@ntu.edu.tw; Chien-Nan Lee* - leecn@ntumc.org

* Corresponding author †Equal contributors
\end{abstract}

Published: 18 September 2006

BMC Medical Genetics 2006, 7:72 doi:10.1 186/147/-2350-7-72
Received: 28 February 2006

Accepted: 18 September 2006

This article is available from: http://www.biomedcentral.com/I47/-2350/7/72

(C) 2006 Hung et al; licensee BioMed Central Ltd.

This is an Open Access article distributed under the terms of the Creative Commons Attribution License (http://creativecommons.org/licenses/by/2.0), which permits unrestricted use, distribution, and reproduction in any medium, provided the original work is properly cited.

\begin{abstract}
Background: Tuberous sclerosis complex (TSC) is an autosomal dominant disease characterized by the development of multiple hamartomas in many internal organs. Mutations in either one of 2 genes, $\mathrm{TSCl}$ and TSC2, have been attributed to the development of TSC. More than two-thirds of TSC patients are sporadic cases, and a wide variety of mutations in the coding region of the TSCI and TSC2 genes have been reported.

Methods: Mutational analysis of TSCI and TSC2 genes was performed in 84 Taiwanese TSC families using denaturing high-performance liquid chromatography (DHPLC) and direct sequencing.

Results: Mutations were identified in a total of 64 (76 \%) cases, including $9 \mathrm{TSCl}$ mutations (7 sporadic and 2 familial cases) and 55 TSC2 mutations (47 sporadic and 8 familial cases). Thirty-one of the 64 mutations found have not been described previously. The phenotype association is consistent with findings from other large studies, showing that disease resulting from mutations to $T S C l$ is less severe than disease due to TSC2 mutation.

Conclusion: This study provides a representative picture of the distribution of mutations of the TSCI and TSC2 genes in clinically ascertained TSC cases in the Taiwanese population. Although nearly half of the mutations identified were novel, the kinds and distribution of mutation were not different in this population compared to that seen in larger European and American studies.
\end{abstract}




\section{Background}

Tuberous sclerosis complex (TSC) is an autosomal dominant disorder having an incidence of 1 in 6,000 to 1 in 10,000 live births [1]. The severity of TSC and its impact on the quality of life are extremely variable among patients [2]. Common clinical manifestations of this disease include intellectual handicap, autistic disorders, and epilepsy due to the frequent, widespread occurrence of cortical tubers, which are focal disruptions of the cortical architecture due to undifferentiated giant cells. Hamartomas are also found in multiple other organ systems, including the heart, lungs, kidneys, and skin [3].

Patients often seek medical attention for dermal lesions or frequent seizures. The clinical diagnostic guidelines on TSC were prepared based on clinical features, radiographic findings, and histopathological findings [3]. Accurate clinical diagnoses are relatively easy in patients with classic multisystem involvement, but are often difficult due to the diversity of clinical findings in TSC patients.

The genetic basis of TSC has been determined to be due to mutation in either one of two unlinked genes, TSC1 and TSC2 [4]. The human TSC1 gene on chromosome 9q34 consists of 23 exons giving an 8.6-kb mRNA transcript, which has a coding region of 3.5-kb and encodes a 130$\mathrm{kDa}$ protein spanning 1164 amino acids [5]. The TSC2 gene, which is located on chromosome 16p13.3, contains 41 exons and encodes a 200-kDa protein with 1807 amino acid $[4,6]$. Both TSC1 and TSC2 are tumor suppressor genes and their protein products, hamartin and tuberin, respectively, form a complex that regulates the mammalian target of rapamycin (mTOR) in the phosphoinositide 3-kinases (PI3-kinase)/AKT pathway to control cellular proliferation, adhesion, growth, differentiation or migration $[7,8]$. Furthermore, both genes play a role in cortical differentiation and growth control.

The mutation spectra of the TSC genes are very heterogeneous and no hotspots for mutations have been reported. There are many mutations in each gene that are seen recurrently, but no single mutation accounts for more than about $1 \%$ of all TSC patients. TSC2 mutations are about five times more common than TSC1 mutations [9] and new mutations are typically found in the two-thirds of TSC cases that are sporadic [10]. Despite complete penetrance of the disease in TSC patients, phenotypic variability can make the determination of disease status difficult among family members of affected individuals.

In this study, we analyzed both TSC1 and TSC2 genes in 84 independent Taiwanese TSC probands for whom detailed information on clinical manifestations and phenotype were available. Furthermore, we also assessed the mutational distribution and possible genotype-phenotype correlations between and within the two genes.

\section{Methods \\ Patient Population}

This study was approved by the Ethics Committee of the Division of Obstetrics and Gynecology, National Taiwan University Hospital. Eighty-four unrelated patients with confirmed clinical diagnoses of TSC and their family members were tested for mutations in TSC1 and TSC2 genes.

The general clinical features of TSC patients were determined by clinicians in accordance with the TSC diagnosis criteria set forth by the Tuberous Sclerosis Consensus Conference [3]. All patients' symptoms were investigated by a person blind to mutational status. High-resolution brain magnetic-resonance imaging (MRI) or computed tomography (CT) was performed on most patients.

The extent of facial angiofibroma or forehead plaques, non-traumatic ungal or periungal fibromas, hypomelanotic macules, shagreen patches, multiple retinal nodular hamartomas, cortical tubers, subependymal nodules, subependymal giant cell astrocytomas, cardiac rhabdomyomas, lymphangiomyomatoses, renal angiomyolipomas and confetti-like lesions were all assessed. Moreover, most patients' medical histories of mental development were assessed by a certified psychologist.

\section{Sample Preparation}

After genetic counseling and obtaining informed consent, 5-10 mL of peripheral blood were collected from the participants. Genomic DNA was isolated from peripheral whole blood using the Puregene DNA Isolation Kit (Gentra Systems, Inc., Minneapolis, MN, USA).

\section{Mutational Analysis of TSC Genes}

PCR primers and running conditions for each exon were available from previous studies [11-13]. The PCR reaction was run on each exon with a total sample volume of $25 \mu \mathrm{L}$ containing $100 \mathrm{ng}$ of genomic DNA, $0.12 \mu \mathrm{M}$ of each respective primer, $100 \mu \mathrm{M}$ dNTPs, $10 \mathrm{mM}$ Tris- $\mathrm{HCl}(\mathrm{pH}$ 8.3), $50 \mathrm{mM} \mathrm{KCl}, 2 \mathrm{mM} \mathrm{MgCl}_{2}$, and 0.5 units of AmpliTaq Gold enzyme (PE Applied Biosystems, Foster City, CA, USA). Amplification was performed in a multiblock system thermocycler (ThermoHybaid, Ashford, UK). The PCR amplification started with a denaturing step at $95^{\circ} \mathrm{C}$ for 5 minutes, followed by 35 cycles of denaturing at $94^{\circ} \mathrm{C}$ for 30 seconds, annealing at melting temperature (Tm) for 30 seconds, extension at $72^{\circ} \mathrm{C}$ for 45 seconds, and ends with a final extension step at $72^{\circ} \mathrm{C}$ for $10 \mathrm{~min}$ utes. 
The screening of mutations was performed using the Transgenomic Wave Nucleic Acid Fragment Analysis System (Transgenomic Inc, San Jose, CA) with a $\mathrm{C}_{18}$ reversedphase column containing $2-\mu \mathrm{m}$ nonporous poly (styrene/ divinylbenzene) particles (DNASep Column, Transgenomic Inc). PCR products were analyzed using linear acetonitrile gradients and triethylammonium acetate acting as mobile phases with the provision of buffer A $(0.1 \mathrm{M}$ TEAA) and buffer B (0.1 M TEAA with $25 \%$ acetonitrile) (WAVE Optimized, Transgenomic Inc). Heteroduplex analyses were performed according to the manufacturer's protocol and of previous studies [14,15].

\section{Statistical method}

The $\chi^{2}$ and Fisher exact tests were used to examine the differences in clinical manifestations, phenotypes, and mutation distributions in independent Taiwanese probands between patients with TSC1 and TSC2 genes.

\section{Direct Sequence Analysis}

PCR products were purified by solid-phase extraction and bidirectionally sequenced using Applied Biosystems' Taq DyeDeoxy terminator cycle sequencing kit (Applied Biosystems). Sequencing reactions were separated on a PE Biosystems 373A/3100 sequencer.

\section{Results and Discussion Identification and Characterization of Mutations}

In the current study, we performed mutational analysis on the coding exons and the exon/intron junctions of both TSC1 and TSC 2 in a total of 84 individuals with TSC and their family members. The determination of mutation vs. polymorphism was done by: 1) checking the mutation tables at the Chromium site (http://chromium.liacs.nl/); 2) comparison of findings to those of 100 healthy Taiwanese controls; and 3) checking the families similarly.
Nine mutations were identified in the TSC1 gene while 55 were identified in the TSC2 gene. Mutations in the TSC1 gene included five nonsense mutations with early termination codons and four insertions/deletions which caused frameshifts and resulted in premature truncation of the protein. Three of these mutations were novel, while six were previously reported (Table 1).

The 55 mutations in the TSC2 gene included 12 missense, 15 nonsense, 21 frameshifts due to insertions and deletions and 7 putative splice-site mutations. Twenty-seven of these mutations were previously reported while 28 were novel (Table 2). Of the familial TSC2 missense mutations, A1141T and R1793Q may be rare polymorphic variants co-segregating with TSC. There was no direct evidence that these familial TSC2 missense mutational changes were pathogenic.

For both genes, sequence variants that were possible mutations were tested in all other family members, including the parents and both the affected and the unaffected family members. In total, 31 of the 64 mutations (48\%) had not been reported elsewhere. Moreover, no mutational hotspots were identified in either gene, with only four different mutations being found twice in TSC2.

Compared with those of European and American counterparts $[9,10,16]$, the distribution of the TSC1 and TSC2 mutations among Taiwanese population is similar. Therefore, the spectrum of mutations seen among the Taiwanese is no different in comparison to those already reported thus far for these two genes, based on the genetic analyses of European and American TSC patients using the Fisher exact test $(P=0.85,0.46$, and 0.14 , respectively).

Table I: Status of TSCI mutations in Taiwanese patients with TSC

\begin{tabular}{|c|c|c|c|c|c|c|c|c|}
\hline No. & Gene & Exon & Nucleotide change & Codon change & Mutation type & Inheritance & Reported & Reference \\
\hline 62 & $\mathrm{TSCl}$ & 7 & c.602_604del CCT & & In-frame deletion & S & $\mathrm{N}$ & This study \\
\hline 61 & $\mathrm{TSCl}$ & 15 & c. $1525 \mathrm{C}>\mathrm{T}$ & p.R509X & Nonsense & $\mathrm{F}$ & $\mathrm{R}$ & {$[5]$} \\
\hline 72 & $\mathrm{TSCl}$ & 15 & c.179I_I792dupAA & & Frameshift & S & $\mathrm{N}$ & This study \\
\hline 2 & $\mathrm{TSCl}$ & 15 & c.1884_I887delAAAG & & Frameshift & $\mathrm{F}$ & $\mathrm{R}$ & {$[5]$} \\
\hline 36 & $\mathrm{TSCl}$ & 15 & c.1959dupA & & Frameshift & S & $\mathrm{R}$ & LOVD* \\
\hline 54 & $\mathrm{TSCl}$ & 17 & c. $2074 C>T$ & p.R692X & Nonsense & S & $R$ & {$[5]$} \\
\hline 31 & $\mathrm{TSCl}$ & 18 & c. $2283 C>A$ & p.Y76IX & Nonsense & $S$ & $\mathrm{R}$ & [24] \\
\hline 3 & $\mathrm{TSCl}$ & 18 & c. $2332 \mathrm{C}>\mathrm{T}$ & P.Q778X & Nonsense & S & $\mathrm{N}$ & This study \\
\hline 41 & $\mathrm{TSCl}$ & 18 & c. $2356 \mathrm{C}>\mathrm{T}$ & p.R786X & Nonsense & S & $\mathrm{R}$ & [5] \\
\hline
\end{tabular}

Total: 9, F:2, S:7, N:3, R:6 MM:0, NM:5, FM:4, SM:0.

F: familial case, S:sporadic case.

$\mathrm{N}$ : non-reported, $\mathrm{R}$ : reported.

MM: missense mutations, NM: nonsense mutations, FM: frameshift/in-frame mutations, SM: splicing site mutations.

* The the Leiden Open (source) Variation Database which was available at http://chromium.liacs.nI/lovd/. 
Table 2: Status of TSC2 mutations in Taiwanese patients with TSC

\begin{tabular}{|c|c|c|c|c|c|c|c|c|}
\hline No. & Gene & Exon & Nucleotide change & Codon change & Mutation type & Inheritance & Reported & Reference \\
\hline 21 & TSC2 & 1 & c. 109dupG & & Frameshift & $\mathrm{F}$ & $\mathrm{N}$ & This study \\
\hline 30 & TSC2 & I & c.133_I36delCTGA & & Frameshift & S & $\mathrm{R}$ & DK* \\
\hline 35 & TSC2 & 3 & c. $268 \mathrm{C}>\mathrm{T}$ & p.Q90X & Nonsense & $S$ & $\mathrm{R}$ & {$[25]$} \\
\hline 47 & TSC2 & 6 & c.632delC & & Frameshift & $S$ & $\mathrm{~N}$ & This study \\
\hline 8 & TSC2 & intron 8 & c. $848+3 \mathrm{delG}$ & & Splicing & S & $\mathrm{N}$ & This study \\
\hline 37 & TSC2 & 9 & $c .856 \mathrm{~A}>\mathrm{G}$ & p.M286V & Missense & $\mathrm{F}$ & $\mathrm{R}$ & {$[10]$} \\
\hline 78 & TSC2 & 10 & c. $1060 \mathrm{C}>\mathrm{T}$ & p.Q354X & Nonsense & S & $\mathrm{N}$ & This study \\
\hline 75 & TSC2 & 10 & c. $1117 \mathrm{C}>\mathrm{T}$ & p.Q373X & Nonsense & S & $\mathrm{R}$ & $\mathrm{DK}^{*}$ \\
\hline 48 & TSC2 & 11 & c.1226_I230delAACTG & & Frameshift & S & $\mathrm{N}$ & This study \\
\hline 12 & TSC2 & 12 & c. $1336 \mathrm{C}>\mathrm{T}$ & p.Q446X & Nonsense & $S$ & $\mathrm{R}$ & {$[25]$} \\
\hline 20 & TSC2 & 14 & c. $1513 C>T$ & p.R505X & Nonsense & $S$ & $\mathrm{R}$ & {$[10]$} \\
\hline 57 & TSC2 & 14 & c. $1513 C>T$ & p.R505X & Nonsense & S & $\mathrm{R}$ & {$[10]$} \\
\hline 65 & TSC2 & intron 14 & c. $1599+2 T>C$ & & Splicing & S & $\mathrm{N}$ & This study \\
\hline 76 & TSC2 & 16 & c. $1794 C>G$ & p.Y598X & Nonsense & $S$ & $\mathrm{R}$ & {$[10]$} \\
\hline 29 & TSC2 & 16 & c. $1832 \mathrm{G}>\mathrm{A}$ & R6IIQ & Missense & S & $\mathrm{R}$ & {$[10]$} \\
\hline 59 & TSC2 & intron 16 & c. $1840-2 A>T$ & & Spilicing & S & $\mathrm{N}$ & This study \\
\hline 82 & TSC2 & 17 & c. $1939 \mathrm{G}>\mathrm{A}$ & p.D647N & Missense & $S$ & $\mathrm{R}$ & [26] \\
\hline 7 & TSC2 & 18 & c. $2086 \mathrm{~T}>\mathrm{C}$ & p.C696R & Missense & $S$ & $\mathrm{R}$ & {$[27]$} \\
\hline 53 & TSC2 & 19 & c.2103_2105dupTGA & & In-frame insertion & $S$ & $\mathrm{~N}$ & This study \\
\hline 5 & TSC2 & 19 & c. $2210 \mathrm{~T}>\mathrm{C}$ & p.L737P & Missense & S & $\mathrm{N}$ & This study \\
\hline 23 & TSC2 & 20 & c. $225 \mid C>T$ & p.R75IX & Nonsense & $S$ & $\mathrm{R}$ & {$[10]$} \\
\hline 70 & TSC2 & 20 & c. $225 I C>T$ & P.R75IX & Nonsense & S & $\mathrm{R}$ & [10] \\
\hline 39 & TSC2 & 21 & c.2404dupA & & Frameshift & $\mathrm{F}$ & $\mathrm{N}$ & This study \\
\hline 32 & TSC2 & 21 & c. $246 \mid \mathrm{A}>\mathrm{T}$ & p.K82IX & Nonsense & $S$ & $\mathrm{~N}$ & This study \\
\hline 11 & TSC2 & 21 & c.2538delC & & Frameshift & $\mathrm{F}$ & $\mathrm{N}$ & This study \\
\hline 67 & TSC2 & intron 2I & c. $2546-2 A>T$ & & Splicing & S & $\mathrm{N}$ & This study \\
\hline 73 & TSC2 & intron 22 & c. $2639+\mid G>C$ & & Splicing & $S$ & $\mathrm{R}$ & [9] \\
\hline 22 & TSC2 & 23 & c.264I delT & & Frameshift & $\mathrm{F}$ & $\mathrm{N}$ & This study \\
\hline 27 & TSC2 & 24 & c. $2824 G>T$ & p.Q942X & Nonsense & S & $\mathrm{N}$ & This study \\
\hline 64 & TSC2 & 26 & c. $2974 C>T$ & p.Q992X & Nonsense & $S$ & $\mathrm{R}$ & {$[28]$} \\
\hline 80 & TSC2 & 26 & c.3076dupT & & Frameshift & S & $\mathrm{N}$ & This study \\
\hline 33 & TSC2 & 28 & c.3389delC & & Frameshift & $S$ & $\mathrm{~N}$ & This study \\
\hline 19 & $\mathrm{TSC} 2$ & 29 & c. $3412 C>T$ & p.RII38X & Nonsense & S & $\mathrm{R}$ & [9] \\
\hline 42 & TSC2 & 29 & c. 342 IG $>A$ & p.AII4IT & Missense & $\mathrm{F}$ & $\mathrm{N}$ & This study \\
\hline 13 & TSC2 & 30 & c.3693_3696delGTCT & & Frameshift & $S$ & $\mathrm{R}$ & $\mathrm{DK}^{*}$ \\
\hline 51 & $\mathrm{TSC} 2$ & 30 & c.3696dupT & & Frameshift & S & $\mathrm{N}$ & This study \\
\hline 9 & TSC2 & 33 & c.4175_4I76delAG & & Frameshift & $S$ & $\mathrm{~N}$ & This study \\
\hline 26 & TSC2 & 33 & c. 4440 dupA & & Frameshift & $S$ & $\mathrm{~N}$ & This study \\
\hline 77 & TSC2 & 34 & c.454I_4544delCAAA & & Frameshift & S & $\mathrm{R}$ & {$[12]$} \\
\hline 18 & TSC2 & 35 & c.4603_4605delGAC & & In-frame deletion & S & $\mathrm{N}$ & This study \\
\hline 34 & TSC2 & 35 & c. $4603 \mathrm{G}>\mathrm{T}$ & p.DI535Y & Missense & $S$ & $\mathrm{~N}$ & This study \\
\hline 83 & TSC2 & 36 & c. $4830 \mathrm{G}>\mathrm{A}$ & p.WI6I0X & Nonsense & S & $\mathrm{R}$ & $\mathrm{DK}^{*}$ \\
\hline 28 & TSC2 & 36 & c. $4846 \mathrm{C}>\mathrm{T}$ & P.Q1616X & Nonsense & $S$ & $\mathrm{~N}$ & This study \\
\hline 16 & TSC2 & 37 & c.4909_4910delAA & & Frameshift & $S$ & $\mathrm{~N}$ & This study \\
\hline 81 & TSC2 & 38 & c.5032dupT & & Frameshift & $S$ & $\mathrm{~N}$ & This study \\
\hline 60 & TSC2 & 39 & c.5150T>C & p.LI7I7P & Missense & $S$ & $\mathrm{R}$ & [29] \\
\hline 55 & TSC2 & intron 39 & c. $5160+3 G>C$ & & Splicing & S & $\mathrm{N}$ & This study \\
\hline 43 & TSC2 & intron 39 & c. $5160+4 A>G$ & & Splicing & $S$ & $\mathrm{R}$ & [29] \\
\hline 4 & TSC2 & 40 & $c .5227 \mathrm{C}>\mathrm{T}$ & p.RI743W & Missense & $S$ & $\mathrm{R}$ & DK* \\
\hline 50 & TSC2 & 40 & c. $5227 \mathrm{C}>\mathrm{T}$ & p.RI743W & Missense & S & $\mathrm{R}$ & $\mathrm{DK}^{*}$ \\
\hline 56 & TSC2 & 40 & c.5228G>A & P.RI743Q & Missense & $\mathrm{F}$ & $\mathrm{R}$ & [30] \\
\hline 10 & TSC2 & 40 & c.5238_5255del I8 & & Frameshift & $S$ & $\mathrm{R}$ & [31] \\
\hline 25 & TSC2 & 40 & c.5238_5255dell 8 & & Frameshift & S & $\mathrm{R}$ & {$[31]$} \\
\hline 6 & TSC2 & 40 & c.5252_5259+19del27 & & Frameshift & $S$ & $\mathrm{R}$ & [9] \\
\hline 15 & TSC2 & 41 & c. $5378 \mathrm{G}>\mathrm{A}$ & p.RI793Q & Missense & $\mathrm{F}$ & $\mathrm{N}$ & This study \\
\hline
\end{tabular}

Total: 55, F:8, S:47, N:28, R:27 MM:12, NM:I5, FM:2I, SM:7.

F: familial case, S:sporadic case.

$\mathrm{N}$ : non-reported, R: reported.

MM: missense mutations, NM: nonsense mutations, FM: frameshift/in-frame mutations, SM: splicing site mutations.

* The database of Dr David Kwiatkowski which was available at http://tsc-project.partners.org/. 


\section{Identification and Characterization of Polymorphism}

In order to identify whether the observed changes were mutations or polymorphisms, samples from 100 normal individuals serving as controls were analyzed. Changes that were not found in more than 200 control alleles were considered pathogenic. Therefore, unique or less frequent changes such as missense and splicing site mutations (Table 2) were considered likely pathogenic mutations. The nonpathogenic TSC1 and TSC2 mutations identified in the Taiwanese TSC patients are described in Table 3. We identified nine nonpathogenic polymorphisms in the TSC1 gene and 12 in the TSC2 gene. The nonpathogenic sequence variants were identified in both the TSC patients and the normal controls. Fourteen of these polymorphisms had not been reported previously (4 at the TSC1 locus and 10 at the TSC2 locus) that included one missense variant within the TSC1 coding region.

\section{Genotype-Phenotype Correlation: Familial or Sporadic TSC mutations}

Mutations were identified and located in exons of both TSC1 and TSC2 genes (see Figure 1 and 2). Of the 64 mutations found, nine and 55 were associated with TSC1 (14\%) and TSC2 (86\%), respectively, as shown in Table 4. Of the 10 familial cases, $2(20 \%)$ and 8 (80\%) were TSC1 and TSC2 mutations, respectively. Among the 54 sporadic cases, 7 TSC1 (13\%) and 47 TSC2 (87\%) mutations were found. Accordingly, there was no significant difference between sporadic and familial TSC cases with respect to the frequency of TSC1 vs TSC2 mutation $(P=$ $0.62)$.

\section{Genotype-Phenotype Correlation: Clinical Manifestations} The clinical characteristics associated with each mutation in the proband are shown in Tables 5 (eight TSC1 mutations) and Table 6 (43 TSC2 mutations). Most patients with TSC1 and TSC2 mutations had seizures, brain lesions (subependymal nodules and/or cortical tubers detected by MRI), and dermal manifestations. Our criteria for intellectual disability included any degree of mental retardation and learning disorder. The incidence of intellectual disability appeared lower in patients with TSC1 mutations $(3 / 8=38 \%)$ compared to that of patients with TSC2 mutations $(27 / 43=63 \%)$. However, this difference

Table 3: Polymorphisms identified for TSCI and TSC2 in Taiwanese TSC population.

\begin{tabular}{|c|c|c|c|c|c|c|}
\hline \multicolumn{7}{|c|}{ TSCI } \\
\hline Exon & Nucleotide change & Codon change & Polymorphism type & Frequency & Reported & Reference \\
\hline Intron 3 & c. $106+15$ & & Intron & 13 (16\%) & $N$ & This study \\
\hline 10 & c.965 T>C & p.M322T & Missense & 9 (II\%) & $\mathrm{R}$ & [24] \\
\hline Intron II & c. $1142-33$ A>G & & Intron & $9(11 \%)$ & $\mathrm{R}$ & LOVDa \\
\hline Intron 12 & c. $1264-12 \mathrm{~T}>\mathrm{C}$ & & Intron & $3(4 \%)$ & $N$ & This study \\
\hline Intron 14 & c. $1437-37$ C>T & & Intron & $9(11 \%)$ & $\mathrm{R}$ & LOVDa \\
\hline 15 & c. $1726 \mathrm{~T}>\mathrm{C}$ & p.L576L & Silent & 11 (13\%) & $N$ & This study \\
\hline 15 & c. $1960 \mathrm{C}>\mathrm{G}$ & p.Q654E & Missense & $3(4 \%)$ & $N$ & This study \\
\hline Intron 18 & c. $2392-35 \mathrm{~T}>\mathrm{C}$ & & Intron & 9 (11\%) & $\mathrm{R}$ & [24] \\
\hline 22 & c. $2829 \mathrm{C}>\mathrm{T}$ & p.A943A & Silent & $3(4 \%)$ & $\mathrm{R}$ & [24] \\
\hline \multicolumn{7}{|c|}{ TSC2 } \\
\hline Exon & Nucleotide change & Codon change & Polymorphism type & Frequency & Reported & Reference \\
\hline 14 & c. $1593 \mathrm{C}>\mathrm{T}$ & p.153II & Silent & $3(4 \%)$ & $\mathrm{R}$ & {$[26]$} \\
\hline Intron 15 & c. $17 \mid 7-30 \mathrm{G}>\mathrm{A}$ & & Intron & $2(2 \%)$ & $N$ & This study \\
\hline Intron 15 & c. $17 \mid 7-27 \mathrm{G}>\mathrm{A}$ & & Intron & I (I \%) & $N$ & This study \\
\hline Intron 21 & c. $2545+45 \mathrm{~T}>\mathrm{A}$ & & Intron & II (13\%) & $N$ & This study \\
\hline 23 & c. $2652 \mathrm{C}>\mathrm{T}$ & p.Y884Y & Silent & I (I \%) & $N$ & This study \\
\hline 26 & c. $3126 \mathrm{G}>\mathrm{T}$ & p.PI042P & Silent & I (I \%) & $\mathrm{R}$ & $\mathrm{DK}^{\mathrm{b}}$ \\
\hline Intron 27 & c. $3285-19$ C>T & & Intron & I (I \%) & $N$ & This study \\
\hline 29 & c.3475 C>T & p.RII59R & Silent & I (I \%) & $N$ & This study \\
\hline 33 & c. $4047 \mathrm{G}>\mathrm{A}$ & p.Al349A & Silent & $2(2 \%)$ & $\mathrm{N}$ & This study \\
\hline Intron 33 & c. $4493+18 \mathrm{G}>\mathrm{A}$ & & Intron & I (I \%) & $N$ & This study \\
\hline Intron 38 & c.5069-2I G>A & & Intron & I (I \%) & $N$ & This study \\
\hline Intron 39 & c.516I-9 C>T & & Intron & 7 (8 \%) & $N$ & This study \\
\hline
\end{tabular}

* Frequence means the number of cases in 84 Taiwanese TSC patients.

a The the Leiden Open (source) Variation Database which was available at http://chromium.liacs.nl/lovd/.

b The database of Dr David Kwiatkowski which was available at http://tsc-project.partners.org/. 


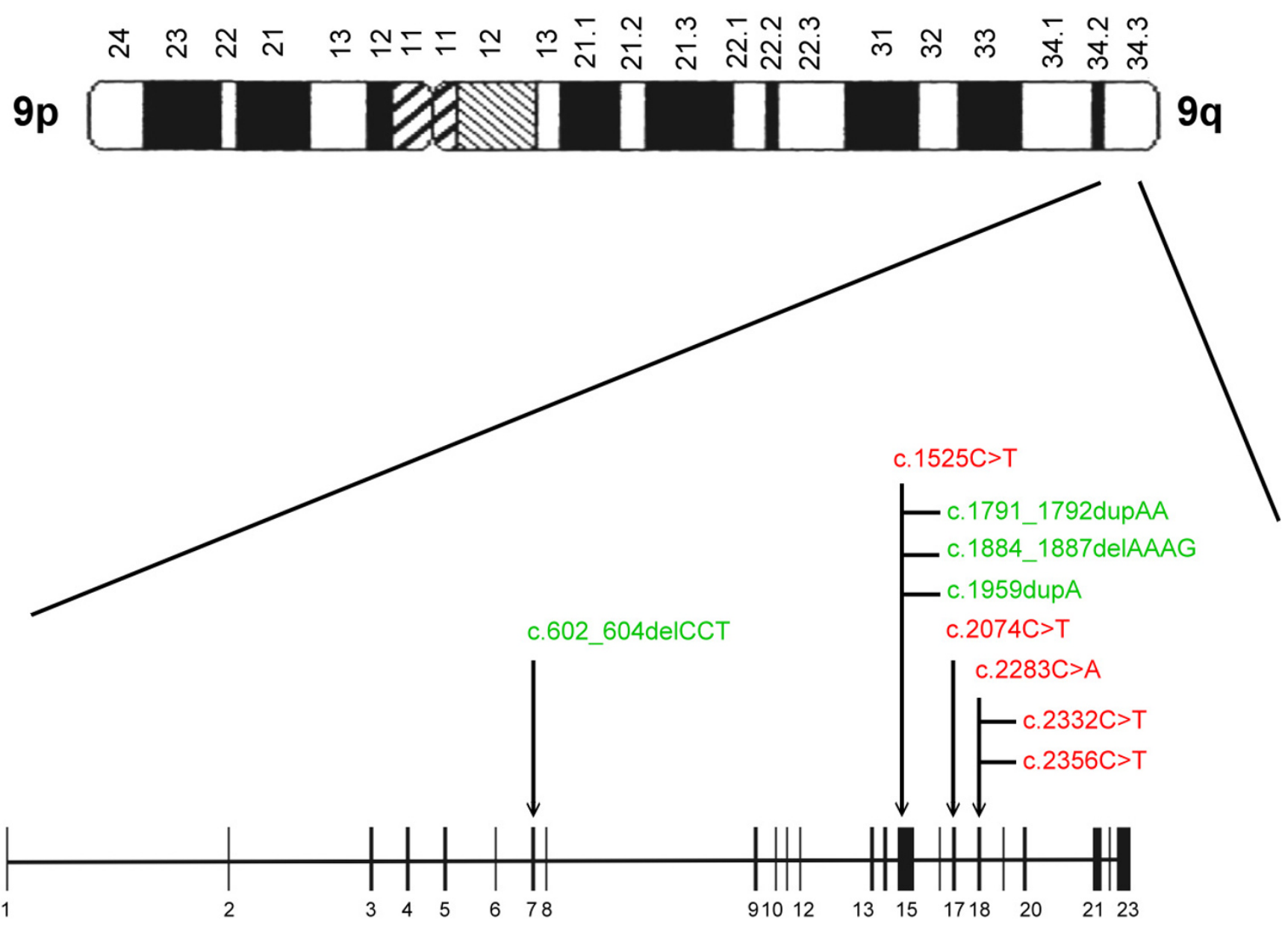

Figure I

Diagram depicting the locations of mutations in the TSCI gene. Nonsense (red), missense (blue), frameshift/in-frame (green) and splicing site (purple) mutations were identified.

was not statistically significant $(P=0.25)$, but this would be expected because of such small sample sizes. Similarly, the incidence of mental retardation in patients with TSC1 mutations $(1 / 8=13 \%)$ appeared to be less than that of patients with TSC2 mutations $(17 / 43=40 \%)$, but this difference was not statistically significant $(P=0.23)$. Similarly, the frequencies of renal findings, cortical tubers, subependymal giant cell astrocytomas, liver tumors, cardiac tumors, or skin manifestations, including hypomelanotic macules, facial angiofibromas, shagreen patches, and ungual fibromas did not significantly differ between the patients with TSC1 and TSC2 mutations. However, all of these comparisons are under-powered due to the relatively small number of patients with TSC1 mutations that were studied. For nearly all of the clinical features studied, the frequencies were less for those bearing TSC1 mutations than for those bearing TSC2 mutations. This is consistent with findings from other large studies, showing that TSC1 disease is less severe than TSC2 disease $[9,10,16]$.

\section{Conclusion}

This study is the first analysis of TSC1 and TSC2 genes in the Taiwanese population. We identified 64 mutations among a total of 84 patients (76\%); 9 were TSC1 mutations (14\%) and 55 were TSC2 mutations (86\%). These numbers are similar to other studies with larger cohorts $[9,10,16-18]$ and would be expected if the germ line mutation rate at the TSC2 locus were higher than that at the TSC1 locus. The failure to detect mutations in the 


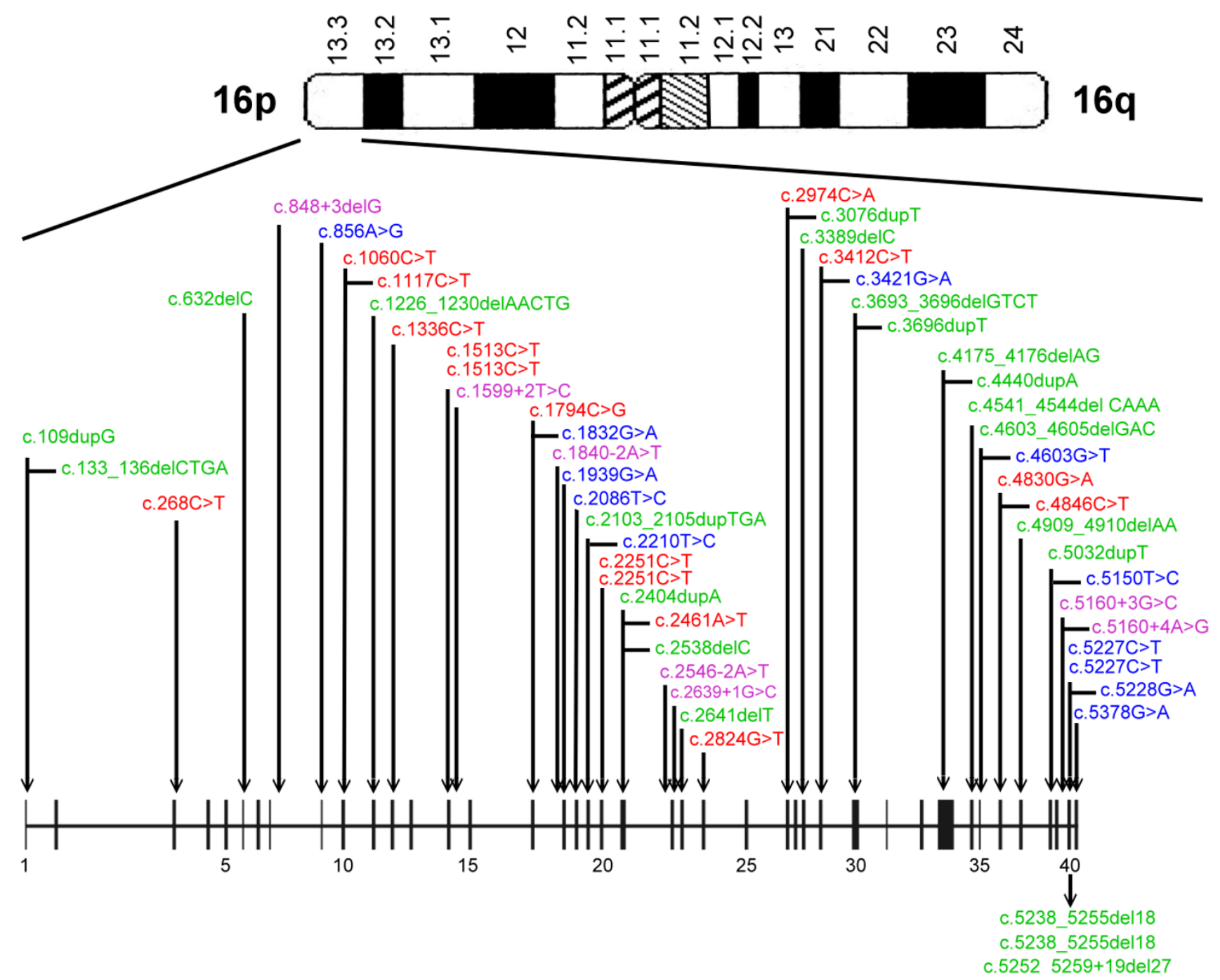

Figure 2

Diagram depicting the locations of mutations in the TSC2 gene. Nonsense (red), missense (blue), frameshift/in-frame (green) and splicing site (purple) mutations were identified.

remaining $24 \%$ of the patients may be due to a combination of lack of screening for large genomic deletion and rearrangement mutations in either TSC1 or TSC2. The occurrence of mosaic mutations $[19,20]$ in some of these patients that may be difficult to detect. Another reason is mutation detection failure.

According to previous reports, somatic and general mosaicism are seen in 6\%-10\% of all TSC patients [20,21]. In addition, large deletions have been identified in about $2 \%-4 \%$ of TSC 2 mutations [6] and less commonly in the TSC1 gene $[22,23]$. Thus, both of these situations likely contributed to patients in which mutations were not identified.

In summary, sixty-four different mutations were identified and characterized for the Taiwanese population. Of those, 31 were not previously described. The diverse mutation spectrum of TSC was also seen in different families and different populations.

\section{Abbreviations}

DHPLC: Denaturing high performance liquid chromatography 


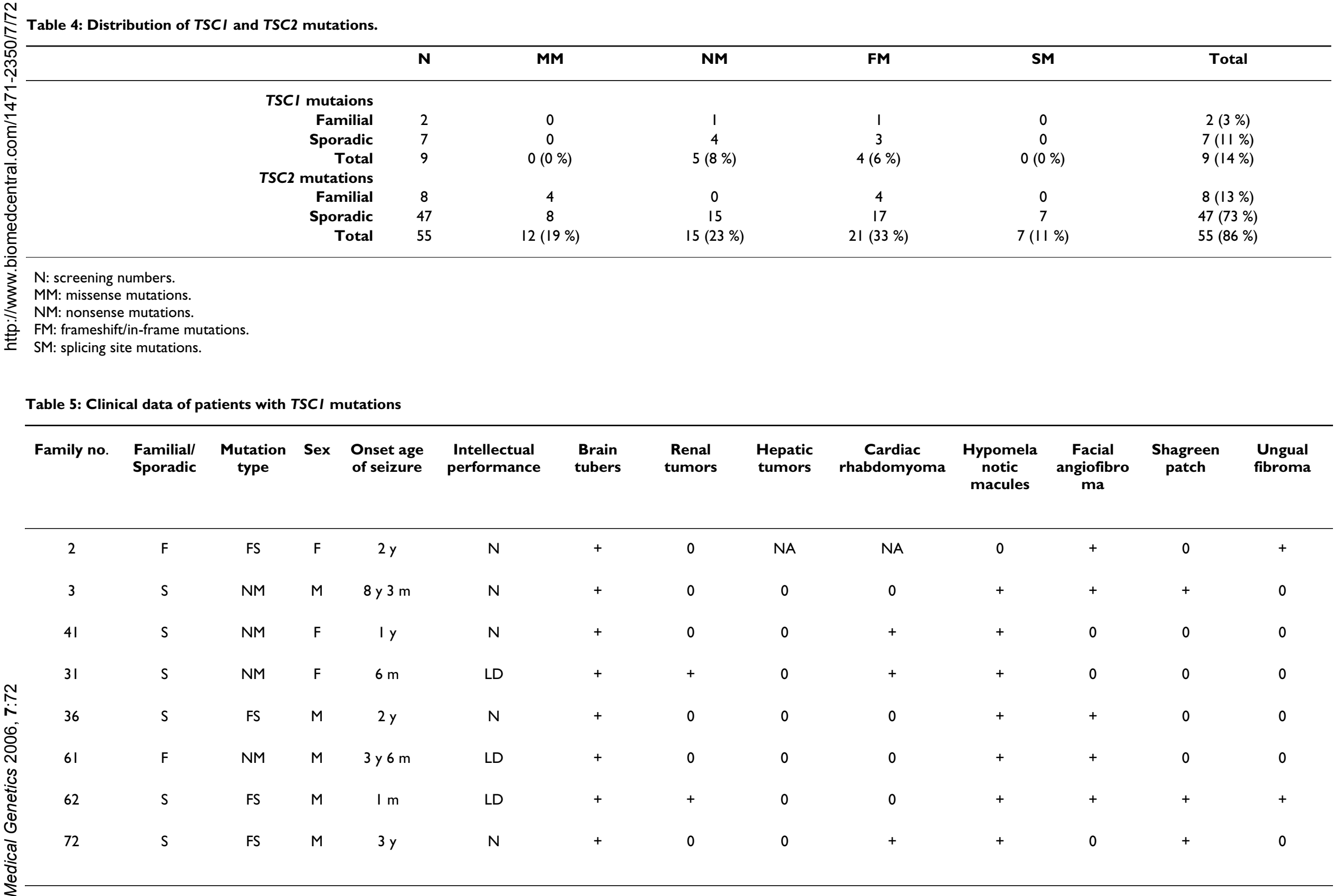




\begin{tabular}{|c|c|c|c|c|c|c|c|c|c|c|c|c|c|}
\hline Family no. & $\begin{array}{l}\text { Familial/ } \\
\text { Sporadic }\end{array}$ & $\begin{array}{c}\text { Mutation } \\
\text { type }\end{array}$ & Sex & $\begin{array}{l}\text { Onset age } \\
\text { of seizure }\end{array}$ & $\begin{array}{l}\text { Intellectual } \\
\text { performance }\end{array}$ & $\begin{array}{l}\text { Brain } \\
\text { tubers }\end{array}$ & $\begin{array}{c}\text { Renal } \\
\text { tumors }\end{array}$ & $\begin{array}{l}\text { Hepatic } \\
\text { tumors }\end{array}$ & $\begin{array}{c}\text { Cardiac } \\
\text { rhabdomyoma }\end{array}$ & $\begin{array}{c}\text { Hypomelano } \\
\text { tic macules }\end{array}$ & $\begin{array}{c}\text { Facial } \\
\text { angiofibroma }\end{array}$ & $\begin{array}{c}\text { Shagreen } \\
\text { patch }\end{array}$ & $\begin{array}{c}\text { Ungual } \\
\text { fibroma }\end{array}$ \\
\hline 4 & S & MM & $M$ & $10 \mathrm{~m}$ & $N$ & + & + & 0 & 0 & + & + & + & 0 \\
\hline 5 & $S$ & MM & $\mathrm{F}$ & Iy & $N$ & + & NA & NA & 0 & + & + & 0 & 0 \\
\hline 6 & $S$ & FS & $M$ & $\mathrm{Im}$ & LD & + & 0 & 0 & + & + & 0 & 0 & 0 \\
\hline 7 & $S$ & MM & $M$ & $6 \mathrm{~m}$ & $M R$ & NA & NA & NA & NA & + & + & 0 & 0 \\
\hline 8 & $S$ & S & $\mathrm{F}$ & $3 \mathrm{~m}$ & LD & + & + & 0 & 0 & + & + & + & 0 \\
\hline 9 & $S$ & FS & $M$ & $5 y$ & LD & + & 0 & 0 & 0 & + & + & + & 0 \\
\hline 10 & $S$ & FS & $\mathrm{F}$ & $6 \mathrm{~m}$ & LD & + & 0 & 0 & + & + & + & 0 & 0 \\
\hline 11 & $\mathrm{~F}$ & FS & $\mathrm{F}$ & $4 \mathrm{~m}$ & LD & + & + & 0 & + & 0 & + & + & 0 \\
\hline 12 & $S$ & NM & $M$ & $10 \mathrm{~m}$ & $N$ & + & + & 0 & NA & + & + & + & 0 \\
\hline 13 & $S$ & FS & $\mathrm{F}$ & $4 \mathrm{~m}$ & $M R$ & + & NA & NA & + & 0 & 0 & 0 & 0 \\
\hline 15 & $\mathrm{~F}$ & MM & $\mathrm{F}$ & $7 \mathrm{~m}$ & MR & + & 0 & 0 & 0 & + & 0 & 0 & 0 \\
\hline 16 & $S$ & FS & $M$ & Iy & $\mathrm{N}$ & + & + & 3 & NA & + & + & + & + \\
\hline 18 & $S$ & FS & $\mathrm{F}$ & $5 \mathrm{~m}$ & LD & + & NA & NA & NA & + & + & + & 0 \\
\hline 19 & $S$ & NM & $M$ & $3 \mathrm{~m}$ & $M R$ & + & + & 0 & NA & + & 0 & 0 & 0 \\
\hline 20 & $S$ & NM & $M$ & 1 y $6 \mathrm{~m}$ & $\mathrm{~N}$ & + & + & 0 & 0 & + & + & 0 & 0 \\
\hline 21 & $\mathrm{~F}$ & $\mathrm{FS}$ & $\mathrm{F}$ & $9 y$ & $\mathrm{~N}$ & + & + & 1 & 0 & + & + & + & + \\
\hline 22 & $\mathrm{~F}$ & FS & $M$ & Iy & LD & NA & NA & NA & NA & + & + & + & 0 \\
\hline 23 & S & NM & $\mathrm{F}$ & $7 \mathrm{~m}$ & $M R$ & + & NA & NA & NA & + & 0 & 0 & 0 \\
\hline 25 & $\mathrm{~S}$ & FS & $M$ & $6 \mathrm{~m}$ & LD & + & 0 & NA & 0 & + & + & + & 0 \\
\hline 26 & $S$ & FS & $\mathrm{F}$ & $8 \mathrm{~m}$ & LD & + & + & 0 & 0 & + & + & + & 0 \\
\hline 27 & $S$ & NM & $M$ & ly & $M R$ & + & + & 0 & 0 & + & + & 0 & 0 \\
\hline 28 & $S$ & NM & $M$ & $3 \mathrm{~m}$ & LD & + & NA & NA & NA & + & + & + & 0 \\
\hline 29 & $\mathrm{~s}$ & MM & $\mathrm{F}$ & $6 \mathrm{~m}$ & $M R$ & + & 0 & NA & 0 & + & 0 & + & 0 \\
\hline 30 & $S$ & FS & $\mathrm{F}$ & Iy & MR & + & + & 0 & 0 & + & + & 0 & 0 \\
\hline 32 & $S$ & NM & $M$ & $3 \mathrm{~m}$ & $N$ & + & + & + & 0 & + & + & 0 & 0 \\
\hline 33 & $S$ & FS & $\mathrm{F}$ & $\mathrm{I} \mathrm{m}$ & $N$ & + & + & + & 0 & + & + & + & + \\
\hline 34 & $S$ & MM & $\mathrm{F}$ & $7 y$ & $N$ & + & + & 0 & 0 & + & 0 & + & 0 \\
\hline 35 & $S$ & NM & $M$ & Iy & MR & + & + & 0 & + & + & + & + & 0 \\
\hline 37 & $\mathrm{~F}$ & MM & $M$ & $9 \mathrm{~m}$ & MR & + & 0 & 0 & + & + & + & + & 0 \\
\hline 39 & $\mathrm{~F}$ & FS & $\mathrm{F}$ & $3 \mathrm{~m}$ & $M R$ & + & NA & NA & NA & + & + & + & 0 \\
\hline 42 & $\mathrm{~F}$ & MM & $M$ & $7 y$ & $\mathrm{~N}$ & 0 & + & + & NA & + & + & + & + \\
\hline 47 & $S$ & FS & $\mathrm{F}$ & $2 \mathrm{~m}$ & $N$ & + & 0 & 0 & + & + & 0 & 0 & 0 \\
\hline 48 & $S$ & FS & $\mathrm{F}$ & $3 \mathrm{~m}$ & $M R$ & + & + & 0 & 0 & + & + & + & 0 \\
\hline 50 & $S$ & MM & $M$ & $3 \mathrm{~m}$ & $M R$ & + & NA & NA & NA & + & + & + & 0 \\
\hline 53 & $S$ & FS & $M$ & $3 y$ & MR & + & + & 0 & 0 & + & + & + & 0 \\
\hline 56 & $\mathrm{~F}$ & MM & $\mathrm{F}$ & $2 y$ & $N$ & + & + & + & 0 & + & + & + & + \\
\hline 57 & $S$ & NM & $\mathrm{F}$ & $6 \mathrm{~m}$ & $M R$ & + & 0 & 0 & 0 & + & + & + & 0 \\
\hline 59 & $S$ & $S$ & $\mathrm{~F}$ & $\mathrm{I} \mathrm{m}$ & $M R$ & + & + & 0 & 0 & + & + & 0 & 0 \\
\hline 64 & $\mathrm{~s}$ & NM & $M$ & $2 \mathrm{~m}$ & $N$ & + & 0 & 0 & 0 & + & 0 & 0 & 0 \\
\hline 67 & $\mathrm{~s}$ & $S$ & $\mathrm{~F}$ & $3 \mathrm{~m}$ & $M R$ & + & 0 & 0 & + & + & + & 0 & 0 \\
\hline 73 & $S$ & $S$ & $\mathrm{~F}$ & $21 y$ & $N$ & + & 0 & 0 & 0 & + & + & 0 & + \\
\hline 75 & $S$ & NM & $\mathrm{F}$ & Iy & $N$ & + & + & 0 & 0 & + & + & 0 & 0 \\
\hline 82 & $S$ & MM & $M$ & $\mathrm{Im}$ & $N$ & 0 & 0 & 0 & + & 0 & 0 & 0 & 0 \\
\hline
\end{tabular}

N: normal or no seizure, LD: learning disorder, MR: metal retardation, NA: not available. 
TSC: Tuberous sclerosis complex

CT: Computed tomography

MRI: Magnetic-resonance imaging

PCR: Polymerase chain reaction

Tm: Melting temperature

\section{Competing interests}

We received financial support in the form of a grant from the National Science Council of Taiwan (NSC 92-2314-B002-319). We have no other competing interests to declare.

\section{Authors' contributions}

$\mathrm{CCH}$ and YNS performed the molecular genetics studies and drafted the manuscript. SCC participated in the molecular genetics studies. HHL and CCC performed the clinical characterization of the patients. $P C C$ and $C J H$ performed the statistical analyses. CPC, WTL and WLL participated in the design of the study. CNL conceived the study, participated in its design and coordination, and helped draft the manuscript. All authors read and approved the final manuscript.

\section{Acknowledgements}

The authors gratefully extend their gratitude to the families and patients affected by TSC for their participation and cooperation in this study. We thank Prof. David Kwiatkowski, Department of Medicine, Brigham and Women's Hospital, Harvard Medical School for deeply review and rewrite the manuscript. We thank Dr. Fon-Jou Hsieh for his expertise and assistance. This work was supported by a grant from the National Science Council of Taiwan (NSC 92-23।4-B-002-319).

\section{References}

I. Osborne JP, Fryer A, Webb D: Epidemiology of tuberous sclerosis. Ann N Y Acad Sci 1991, 6 I 5:125-127.

2. Gomez MR SJRHWV: Tuberous sclerosis complex. 3rd edn New York: Oxford University Press 1999.

3. Roach ES, Gomez MR, Northrup H: Tuberous sclerosis complex consensus conference: revised clinical diagnostic criteria. J Child Neurol 1998, I3(12):624-628.

4. Povey S, Burley MW, Attwood J, Benham F, Hunt D, Jeremiah SJ, Franklin D, Gillett G, Malas S, Robson EB, et al.: Two loci for tuberous sclerosis: one on 9q34 and one on 16p I3. Ann Hum Genet 1994, 58 (Pt 2): 107-127.

5. van Slegtenhorst M, de Hoogt R, Hermans C, Nellist M, Janssen B, Verhoef S, Lindhout D, van den Ouweland A, Halley D, Young J, Burley M, Jeremiah S, Woodward K, Nahmias J, Fox M, Ekong R, Osborne J, Wolfe J, Povey S, Snell RG, Cheadle JP, Jones AC, Tachataki M, Ravine D, Sampson JR, Reeve MP, Richardson P, Wilmer F, Munro C, Hawkins TL, Sepp T, Ali JB, Ward S, Green AJ, Yates JR, Kwiatkowska J, Henske EP, Short MP, Haines JH, Jozwiak S, Kwiatkowski DJ: Identification of the tuberous sclerosis gene TSCI on chromosome 9q34. Science 1997, 277(5327):805-808.

6. The European Chromosome 16 Tuberous Sclerosis Consortium.: Identification and characterization of the tuberous sclerosis gene on chromosome 16. The European Chromosome 16 Tuberous Sclerosis Consortium. Cell 1993, 75(7): 1305-1315.

7. Astrinidis A, Henske EP: Tuberous sclerosis complex: linking growth and energy signaling pathways with human disease. Oncogene 2005, 24(50):7475-7481.
8. Kwiatkowski DJ, Manning BD: Tuberous sclerosis: a GAP at the crossroads of multiple signaling pathways. Hum Mol Genet 2005, I 4 Spec No. 2:R25I-8.

9. Dabora SL, Jozwiak S, Franz DN, Roberts PS, Nieto A, Chung J, Choy YS, Reeve MP, Thiele E, Egelhoff JC, Kasprzyk-Obara J, DomanskaPakiela D, Kwiatkowski DJ: Mutational analysis in a cohort of 224 tuberous sclerosis patients indicates increased severity of TSC2, compared with TSCI, disease in multiple organs. Am J Hum Genet 200I, 68(I):64-80.

10. Jones AC, Shyamsundar MM, Thomas MW, Maynard J, Idziaszczyk S, Tomkins S, Sampson JR, Cheadle JP: Comprehensive mutation analysis of TSCI and TSC2-and phenotypic correlations in I50 families with tuberous sclerosis. Am J Hum Genet 1999, 64(5): $1305-1315$.

II. Jones AC, Daniells CE, Snell RG, Tachataki M, Idziaszczyk SA, Krawczak M, Sampson JR, Cheadle JP: Molecular genetic and phenotypic analysis reveals differences between TSCI and TSC2 associated familial and sporadic tuberous sclerosis. Hum Mol Genet 1997, 6(1 2):2155-2161.

12. Maheshwar MM, Cheadle JP, Jones AC, Myring J, Fryer AE, Harris PC, Sampson JR: The GAP-related domain of tuberin, the product of the TSC2 gene, is a target for missense mutations in tuberous sclerosis. Hum Mol Genet 1997, 6(1 I):199I-1996.

13. Maheshwar MM, Sandford R, Nellist M, Cheadle JP, Sgotto B, Vaudin $M$, Sampson JR: Comparative analysis and genomic structure of the tuberous sclerosis $\mathbf{2}$ (TSC2) gene in human and pufferfish. Hum Mol Genet 1996, 5(1): | 31-।37.

14. Su YN, Lee CN, Hung CC, Chen CA, Cheng WF, Tsao PN, Yu CL, Hsieh FJ: Rapid detection of beta-globin gene (HBB) mutations coupling heteroduplex and primer-extension analysis by DHPLC. Hum Mutat 2003, 22(4):326-336.

15. Xiao W, Oefner PJ: Denaturing high-performance liquid chromatography: A review. Hum Mutat 200I, 17(6):439-474.

16. Sancak O, Nellist M, Goedbloed M, Elfferich P, Wouters C, MaatKievit A, Zonnenberg B, Verhoef S, Halley D, van den Ouweland A: Mutational analysis of the TSCI and TSC2 genes in a diagnostic setting: genotype--phenotype correlations and comparison of diagnostic DNA techniques in Tuberous Sclerosis Complex. Eur J Hum Genet 2005, I3(6):73I-74I.

17. Lewis JC, Thomas HV, Murphy KC, Sampson JR: Genotype and psychological phenotype in tuberous sclerosis. J Med Genet 2004, 4I(3):203-207.

18. Jones AC, Sampson JR, Hoogendoorn B, Cohen D, Cheadle JP: Application and evaluation of denaturing HPLC for molecular genetic analysis in tuberous sclerosis. Hum Genet 2000, 106(6):663-668.

19. Kwiatkowska J, Wigowska-Sowinska J, Napierala D, Slomski R, Kwiatkowski DJ: Mosaicism in tuberous sclerosis as a potential cause of the failure of molecular diagnosis. N Engl J Med 1999, 340(9):703-707.

20. Sampson JR, Maheshwar MM, Aspinwall R, Thompson P, Cheadle JP, Ravine D, Roy S, Haan E, Bernstein J, Harris PC: Renal cystic disease in tuberous sclerosis: role of the polycystic kidney disease I gene. Am J Hum Genet I997, 6 I(4):843-85I.

21. Verhoef S, Bakker L, Tempelaars AM, Hesseling-Janssen AL, Mazurczak T, Jozwiak S, Fois A, Bartalini G, Zonnenberg BA, van Essen AJ, Lindhout D, Halley DJ, van den Ouweland AM: High rate of mosaicism in tuberous sclerosis complex. Am J Hum Genet 1999, 64(6): $1632-1637$

22. Nellist M, Sancak O, Goedbloed MA, van Veghel-Plandsoen M, MaatKievit $A$, Lindhout $D$, Eussen $B H$, de Klein A, Halley $D$ J, van den Ouweland AM: Large deletion at the TSCI locus in a family with tuberous sclerosis complex. Genet Test 2005, 9(3):226-230.

23. Longa L, Saluto A, Brusco A, Polidoro S, Padovan S, Allavena A, Carbonara $\mathrm{C}$, Grosso E, Migone N: TSCI and TSC2 deletions differ in size, preference for recombinatorial sequences, and location within the gene. Hum Genet 200I, 108(2): I56-I66.

24. Dabora SL, Sigalas I, Hall F, Eng C, Vijg J, Kwiatkowski DJ: Comprehensive mutation analysis of TSCI using two-dimensional DNA electrophoresis with DGGE. Ann Hum Genet 1998, 62 ( Pt 6):49I-504.

25. Choy YS, Dabora SL, Hall F, Ramesh V, Niida Y, Franz D, KasprzykObara J, Reeve MP, Kwiatkowski DJ: Superiority of denaturing high performance liquid chromatography over singlestranded conformation and conformation-sensitive gel elec- 
trophoresis for mutation detection in TSC2. Ann Hum Genet 1999, 63 ( Pt 5):383-391.

26. Zhang $H$, Nanba E, Yamamoto T, Ninomiya H, Ohno K, Mizuguchi M, Takeshita K: Mutational analysis of TSCI and TSC2 genes in Japanese patients with tuberous sclerosis complex. J Hum Genet 1999, 44(6):391-396.

27. Roberts PS, Ramesh V, Dabora S, Kwiatkowski DJ: A 34 bp deletion within TSC2 is a rare polymorphism, not a pathogenic mutation. Ann Hum Genet 2003, 67(Pt 6):495-503.

28. Beauchamp RL, Banwell A, McNamara P, Jacobsen M, Higgins E, Northrup H, Short P, Sims K, Ozelius L, Ramesh V: Exon scanning of the entire TSC2 gene for germline mutations in 40 unrelated patients with tuberous sclerosis. Hum Mutat 1998, I 2(6):408-4I6.

29. Chen CP, Su YN, Hung CC, Lee CN, Hsieh FJ, Chang TY, Chen MR, Wang W: Molecular genetic analysis of the TSC genes in two families with prenatally diagnosed rhabdomyomas. Prenat Diagn 2005, 25(2): 176-I78.

30. Ichikawa T, Wakisaka A, Daido S, Takao S, Tamiya T, Date I, Koizumi S, Niida $Y$ : A case of solitary subependymal giant cell astrocytoma: two somatic hits of TSC2 in the tumor, without evidence of somatic mosaicism. J Mol Diagn 2005, 7(4):544-549.

31. Niida Y, Lawrence-Smith N, Banwell A, Hammer E, Lewis J, Beauchamp RL, Sims K, Ramesh V, Ozelius L: Analysis of both TSCI and TSC2 for germline mutations in 126 unrelated patients with tuberous sclerosis. Hum Mutat 1999, I4(5):4I2-422.

\section{Pre-publication history}

The pre-publication history for this paper can be accessed here:

http://www.biomedcentral.com/1471-2350/7/72/prepub

Publish with Bio Med Central and every scientist can read your work free of charge

"BioMed Central will be the most significant development for disseminating the results of biomedical research in our lifetime. "

Sir Paul Nurse, Cancer Research UK

Your research papers will be:

- available free of charge to the entire biomedical community

- peer reviewed and published immediately upon acceptance

- cited in PubMed and archived on PubMed Central

- yours - you keep the copyright 